International Journal of Advanced Research and Development

ISSN: 2455-4030

Impact Factor: RJIF 5.24

www.advancedjournal.com

Volume 3; Issue 4; July 2018; Page No. 187-188

\title{
Impact of high school on social development
}

\author{
Jayanta Dasgupta $^{1}$, Dr. Nidhi Agarwal ${ }^{2}$ \\ ${ }^{1}$ Research Scholar, Kalinga University, Naya Raipur, Chhattisgarh, India \\ ${ }^{2}$ Supervisor, Kalinga University, Naya Raipur, Chhattisgarh, India
}

\begin{abstract}
In assessing the writing on the social effect of secondary school, six subjects were distinguished: understudies see solid standards for adjustment to class governs, the accentuation on congruity and control impacts the nature of understudy/educator relations which have a tendency to be part bound and unbendable, ways to economic wellbeing keep on emphasizing athletic capability, peer aggregate recognizable proof affects social relations inside the bigger group and in addition in the school setting, frailty is felt because of the dictator way to deal with basic leadership, and the general secondary school condition does not upgrade understudies' convictions in the Bill of Rights. It was reasoned that secondary school understudies have constrained open doors for adaptable self-definition. Because of the way they are dealt with by expert figures and the solid weights toward congruity, numerous teenagers neglect to take in the degree of their rights or viable methodologies for the activity of energy.
\end{abstract}

Keywords: social, school

\section{Introduction}

New educators juggle a mind-boggling number of new issues, for example, classroom administration, direction, educational programs, school culture and tasks, test planning and organization, state measures, parent relations, and connections with different instructors. Left to themselves, they may create counterproductive practices. With additional help, be that as it may, new educators take in more powerful practices to apply to day by day challenges. Extra help additionally enables locale to hold new instructors and put them on the way to getting to be viable teachers. Numerous educational systems give coaches and acceptance projects to tenderfoot educators. These projects are required in numerous states for educators to procure an expert permit. Above all, explore demonstrates that new educators who got serious tutoring significantly affected understudy accomplishment after as meager as two years.

\section{Review of Literature}

Katrina M. Walsemann, (2010) directed an investigation on Integrated Schools, Segregated Curriculum: Effects of WithinSchool Segregation on Adolescent Health Behaviors and Educational Aspirations. The goal of the examination was to look at the degree to which inside school isolation, as estimated by unevenness in the circulation of Black and White teenagers crosswise over levels of the English educational programs (propelled arrangement worldwide baccalaureaterespects, general, therapeutic, or no English), was related with smoking, drinking, and instructive yearnings, which past investigations found are identified with school racial/ethnic piece. The information was gathered from wave 1 of the National Longitudinal Study of Adolescent Health, confining our example to non-Hispanic Blacks $(\mathrm{n}=2731)$ and Whites ( $\mathrm{n}$ $=4158$ ) who from 1994 to 1995 went to secondary schools that enlisted Black and White understudies. It was discovered that white female understudies had higher anticipated probabilities of smoking or drinking than blacked female understudies. The biggest contrasts were in schools with abnormal amounts of inside school isolation. Dark male understudies had higher anticipated probabilities of high instructive goals than white male understudies in schools with low levels of inside school isolation. This affiliation was lessened for Black guys going to schools with direct or abnormal amounts of inside school isolation. The examination presumes that inside school isolation may impact the two understudies' goals and their practices.

Fadael, (2011) directed an examination entitled "The connection between school adequacy and understudy accomplishment: An investigation of center school execution in Palm Beach County, Florida since the usage of NCLB". The motivation behind this co social examination was to inquire about the connection between school viability and understudy accomplishment among center school students in a high-destitution, high-minority populated zone in Palm Beach County, Florida. A five year school review of A was benchmarked to recognize the low performing and high performing schools. The investigation found that low performing minority schools had bring down composing test scores than high performing blended ethnicity schools and furthermore had bring down FCAT Math, Reading and Science scores than high performing minority schools. Instructors' apparent school adequacy appraisals were found to relate altogether with understudy accomplishment. Chance to learn and time on assignment, visit checking o understudy advance and positive self-teach connection showed noteworthy positive associations with making learning picks up in perusing and math. 


\section{School Environments}

A school's social condition has expansive effect on understudies' learning and development, including real parts of their social, enthusiastic, and moral improvement. The social condition is formed by numerous components:

- The school's upheld objectives and qualities

- The essential's initiative style

- The workforce's instructing and train techniques

- The arrangements in regards to evaluating and following

- The incorporation or avoidance of understudies and guardians in the arranging and

- decision-production forms

The significance of the school condition is underscored by the Search Institute's rundown of ecological and individual "formative resources" that fill in as general defensive elements. Among the things in the foundation's rundown of ecological resources are:

- A minding school atmosphere

- Parental inclusion in tutoring

- Clear standards and results in the school and family

- High desires from educators and guardians

Among the things in the establishment's rundown of individual resources are:

- Motivation to accomplish

- School engagement

- Bonding to class

These terms are utilized reciprocally here since they all allude to understudies' feeling of being in close, aware associations with companions and grown-ups in school or of being contributing and compelling individuals from the school.

Why is advancing group in school turned out to be so vital? For what reason does it have such wide impacts on understudies' improvement? At the point when these essential needs are satisfied, understudies will probably end up occupied with, and focused on, the school and, accordingly, slanted to carry on as per its communicated objectives and qualities As understudies turn out to be more skilled and slanted to add to the steady school setting, they basically advance, alongside the school's staff, an "upward winding" by which group is fortified and those engaged with it are further profited.

\section{Conclusion}

At the point when understudies' essential mental needs (wellbeing, having a place, self-sufficiency, and skill) are fulfilled, they will probably:

- Become occupied with (school holding)

- Act as per school objectives and qualities

- Develop social aptitudes and comprehension

- Contribute to the school and the group

It is measured that schools neglect to address understudies' issues for having a place, skill, and self-rule, understudies will probably progress toward becoming:

- Less persuaded

- More estranged

- Poorer scholastic entertainers
In this manner, understudies who is regularly most needing a strong school condition might be set at a further drawback by the nature of their involvement in school. A few analysts on inspiration trust that when schools neglect to address understudies' issues for having a place (or capability and selfrule), understudies will turn out to be less persuaded, more estranged, and poorer entertainers.

\section{References}

1. Mehmet Fatih Ayaz. The Effects of the Constructivist Learning Approach on Student's Academic Achievement: A Meta-Analysis Study, TOJET: The Turkish Online Journal of Educational Technology. 2015; 14(4):143-146.

2. Mustafa KOC. Implications of Learning Theories for Effective Technology Integration and Pre-service Teacher Training: A Critical Literature Review, Journal of Turkish science education. 2015; 2(1):1-18.

3. Liker Cirik. constructivist learning environments: the teachers' and students' perspectives, International Journal on New Trends in Education and Their Implications. 2015; 6(2):30-44.

4. Holmboe ES. Making self-assessment more effective, Journal of Continuing Education in the Health Professions. 2013; 83(1):32-45.

5. Nancy Evans J. The architectural design studio as a learning environment: a qualitative exploration of architecture design student learning experiences in design studios from first- through fourth-year, international journal of research. 2008; 67(2):200-225.

6. Bada. Constructivism Learning Theory: A Paradigm for Teaching and Learning, Journal of Research \& Method in Education. 2015; 5(6):66-70.

7. Lori Harkness M. The Effect of a Constructivist-Based Approach on Fifth Grade Reading Achievement, International Journal Research. 2016; 29(3):1-62. 